\title{
Re-operative abdominal predictive score: a prognostic model combining Acute Re-intervention Predictive Index and intra-abdominal pressure
}

\author{
Caridad de Dios Soler-Morejón ${ }^{1}$, Tomás Ariel Lombardo-Vaillant ${ }^{2}$, Teddy Osmín Tamargo-Barbeito ${ }^{3}$, \\ Robert Wise ${ }^{4}$, Manu L.N.G. Malbrain ${ }^{5,6}$ \\ ${ }^{1}$ Intensive Care Unit, Hermanos Ameijeiras Hospital, Havana, Cuba \\ ${ }^{2}$ Surgery Department, Calixto García Medical Faculty, Havana, Cuba \\ 3Biostatistics' Department, Hermanos Ameijeiras Hospital, Havana, Cuba \\ ${ }^{4}$ Cert Crit Care, Discipline of Anaesthesiology and Critical Care, School of Clinical Medicine, \\ University of KwaZulu-Natal, Durban, South Africa \\ 5Intensive Care, ICU and High Care Burn Unit, Director, Ziekenhuis Netwerk Antwerpen, ZNA Stuivenberg, \\ Antwerp, Belgium \\ ${ }^{6}$ ICU Director, University Hospital Brussels (UZB), Jette, Belgium, Professor at Vrije Universiteit Brussel (VUB), \\ Faculty of Medicine, Brussels, Belgium
}

\begin{abstract}
Background: The decision to re-operate after abdominal surgery is still difficult, especially in the setting of intraabdominal sepsis. Mathematical models provide a good aid to both diagnosis and decision-making.

Methods: A prospective observational study was conducted with 300 patients consecutively admitted to the intensive care unit of an academic institution affiliated to Calixto García Medical Faculty following abdominal surgery from January 2008 to January 2010. The patients were randomly separated (2:1) into estimation and validation groups. Logistic regression analysis was used in the estimation group to develop three models for decision-making related to re-operation including related factors such as age, ARPI, IAP, type of surgery (elective or emergency), and the duration of surgery. The three models developed were validated on the other group.

Results: The acute re-operation predictive index-intra-abdominal pressure (ARPI-IAP) model was the best of the three models, with an excellent calibration, using the Hossmer-Lemeshow goodness-of-fit statistical test $(C=9.976$, $P=0.267$ ), as well as discrimination (AUC $=0.989 ; 95 \% \mathrm{Cl}: 0.976-1.000$ ).

Conclusion: The combination of IAP with ARPI in a mathematical model can add accuracy to the prediction of need for re-operation related to intra-abdominal infectious complications in patients following abdominal surgery. This may be useful in all medical settings, but especially those with limited resources.
\end{abstract}

Anaesthesiology Intensive Therapy 2017, vol. 49, no 5, 358-365

Key words: intra-abdominal pressure, acute re-operation predictive index, prognostic model, abdominal re-operation

Currently, there is no consensus guiding surgeons when to re-operate on patients with intra-abdominal sepsis. Although advancement in radiological imaging has improved diagnostic ability, it does not provide clear answers in every case decision following abdominal surgery [1, 2]. Decisions regarding surgical plans, admission to intensive care units, and prognosis are generally made using a combination of clinical examination, personal experience, and diagnostic tests. Scoring systems and severity indices are not widely used, even though there is extensive evidence to their usefulness in research and audit purposes [3]. In general, it is considered that scoring systems are not consistent enough 
Table 1. Characteristics of the surgical patients in the estimation and validation groups

\begin{tabular}{|c|c|c|c|c|}
\hline & & $\begin{array}{c}\text { EG group } \\
n=200\end{array}$ & $\begin{array}{l}\text { VG group } \\
n=100\end{array}$ & $P$-value \\
\hline Males & & $126(63.0 \%)$ & $62(62.0 \%)$ & \\
\hline Females & & 74 (37.0\%) & $38(38.0 \%)$ & $0.966^{\mathrm{a}}$ \\
\hline Age (years) & & $53.4 \pm 19.8$ & $58.2 \pm 19.8$ & $0.048^{b}$ \\
\hline \multirow[t]{2}{*}{ Comorbidity } & Yes & 192 (96.0\%) & 96 (96.0\%) & $0.755^{\mathrm{a}}$ \\
\hline & No & $8(4.0 \%)$ & $4(4.0 \%)$ & \\
\hline \multirow[t]{2}{*}{ Re-operation } & Yes & $71(35.5 \%)$ & 31 (31.0\%) & $0.518^{a}$ \\
\hline & No & 129 (64.5\%) & $69(69.0 \%)$ & \\
\hline \multirow[t]{2}{*}{ Malignancy } & Yes & $9(4.5 \%)$ & $4(4.0 \%)$ & $0.920^{\mathrm{a}}$ \\
\hline & No & 191 (95.5\%) & $96(96.0 \%)$ & \\
\hline $\mathrm{IAP}(\mathrm{mm} \mathrm{Hg})$ & & $12.2 \pm 5.4$ & $12.1 \pm 5.4$ & $0.821^{b}$ \\
\hline APACHE II & & $16.5 \pm 6.0$ & $16.0 \pm 5.9$ & $0.506^{b}$ \\
\hline Mortality & & $17(8.5 \%)$ & $7(7.0 \%)$ & $0.821^{a}$ \\
\hline
\end{tabular}

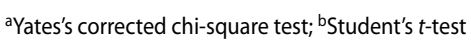

to predict the outcome of surgical patients on an individual basis [3] Currently, there is no ideal score for the prediction of ongoing infection in patients with abdominal sepsis after their initial emergency laparotomy. As Van Ruler et al. [4] reported, APACHE-II score, SAPS-II, Mannheim Peritonitis Index (MPI), MODS, SOFA score, and the acute part of the APACHE-II score (APS) were evaluated and none of them were of clinical value in this group of patients [4]. However, these scoring systems can be combined with risk factors for IAH to develop prediction models. Prediction modelling is a useful tool for the assessment and evaluation of underlying pathological conditions within a specified patient population [5].

The abdominal re-operation predictive index (ARPI) [1] is useful in surgical decision-making in patients with complications following surgery. Although in our experience its specificity was 100\%, its sensitivity was $72.9 \%$ (95\% Cl 70.9-73.3) [2]. Intra-abdominal pressure (IAP) is an independent risk factor for complications and mortality following abdominal surgery [6]. This study hypothesised that the combination of IAP and ARPI in a mathematical model, could improve the prognostic accuracy of re-operation when used in patients with intra-abdominal infectious complications after abdominal surgery.

\section{METHODS}

A prospective observational study was performed including 300 consecutive surgical patients admitted to the intensive care unit of an academic institution affiliated to Calixto García Medical Faculty following abdominal surgery between January 2008 and January 2010. The inclusion criteria were: a) postoperative adult patients following emergency or elective abdominal surgery and; b) admission to the intensive care unit for 48 hours or more. Exclusion criteria included as follows: pregnant women; re-operation for noninfectious causes; planned re-operation; patients in which it was not possible to measure IAP; and patients who died within the first 48 hours of admission.

The patients were randomized into two groups in a ratio of 2:1; an estimation/model development group (EG) and a validation group (VG). The dependent variable was re-operation, while the independent variables were age, ARPI, IAP, type of surgery (elective or emergency), and the duration of surgery. ARPI was calculated using the various parameters (including urgent surgery, respiratory failure, renal failure, ileus 72 hours after surgery, abdominal pain 48 hours after surgery, infection of the surgical wound, mental alteration, and new symptoms after the fourth day of surgery) [1] since the first postoperative day, during the morning clinical assessment. In order to limit inter-observer variability, specialists (including intensivists and surgeons) calculated the ARPI independently and blinded to each other. A mean value was calculated following this process. In the non-reoperated patients, the highest ARPI calculated during the postoperative period was considered (Table 1) [1].

The IAP was measured in each patient according to Cheatham and Safcsak's technique [7] and the World Society of Abdominal Compartment Syndrome's (WSACS) recommendations [8]. Instead of using a transducer, a column of water (with a centimetre of water scale) was added to the urinary drainage system (Fig. 1).

Two end-expiratory IAP measurements were performed, by trained nurses under the supervision of a specialist, six hours apart during the first 24 hours of admission. All WSACS recommendations were followed during this process. The 


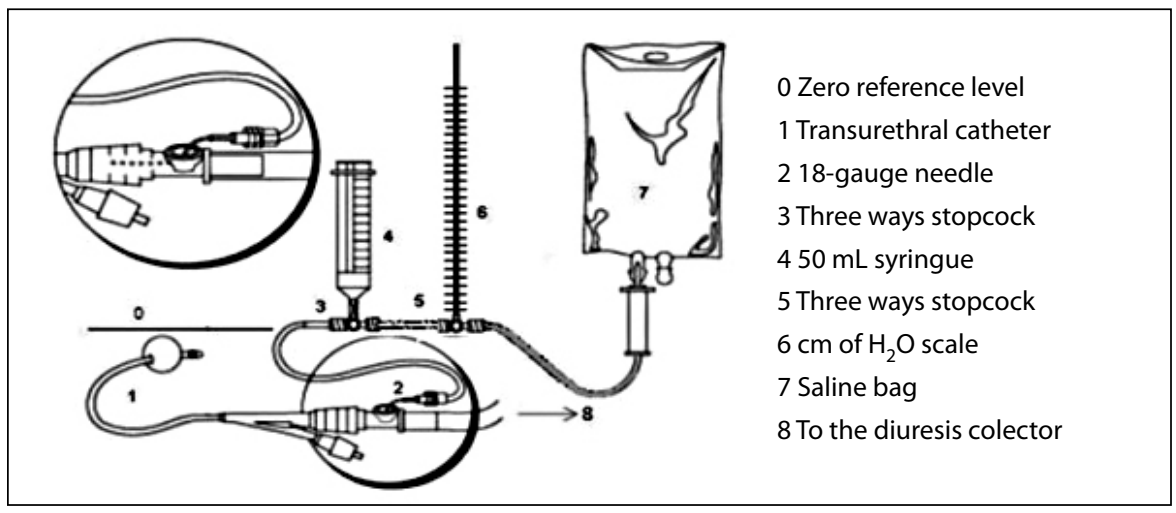

Figure 1. Schematic drawing of abdominal pressure measurement technique. A centimetre of water scale is inserted into the system to directly measure the intra-abdominal pressure. Adapted from Cheatham and Safcsak's technique [7]

four IAP values obtained in each patient were converted to millimetres of mercury and averaged. APACHE II severity scores were also recorded [9].

The decision to re-operate was made according to a clinical evaluation, an ARPI decision algorithm and the IAP value. IAH was diagnosed when IAP was above $12 \mathrm{~mm} \mathrm{Hg}$ in two consecutive measurements [8]. Surgical procedures performed included partial resection, anastomosis and stoma surgery according to intra-operative findings. In a subsequent surgery, the pending problems from the preceding operation were solved and anastomoses were performed when possible.

The findings during re-operation were considered the final confirmation of intra-abdominal infectious complications. Each patient's outcome was followed until discharge from hospital or death.

\section{DATA MANAGEMENT AND STATISTICAL ANALYSIS}

The Statistical Package for Social Sciences (SPSS for Windows version $11.5^{\circ}$ software SPSS Inc., Chicago, IL, USA) was used to analyze data. The statistical analysis flow diagram is shown in Figure 2. The indicators of central tendency and dispersion comprised the following: means, standard deviations and $95 \%$ confidence intervals $(\mathrm{Cl})$ were estimated for quantitative variables, while frequencies and percentages were used for qualitative variables. The chi-squared test with Yates's correction for continuity was used wherever appropriate in order to identify the differences between categorical variables. Student's $t$-test was used to compare mean differences for continuous variables in baseline characteristics between groups.

The 300 eligible patients were randomized into two groups: 200 for the EG, and 100 for the VG. The logistic regression model parameters were estimated in the EG. TheVG allowed one to check the actual prediction capacity of the models for new patients. Three logistic regression models

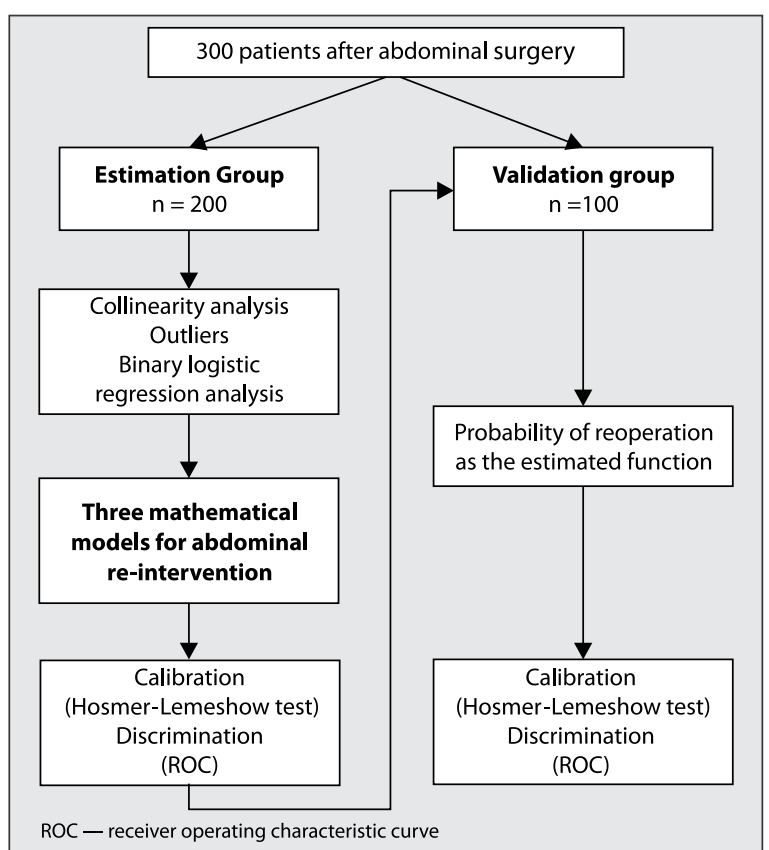

Figure 2. Statistical analysis flow diagram 300 patients after abdominal surgery

were developed to analyse the influence of a set of variables in the probability of re-operation:

- Model I (ARPI): Independent variables: age, sex, ARPI, type of surgery and duration of surgery

- Model II (IAP): Independent variables: age, sex, IAP, type of surgery and duration of surgery

- Model III (ARPI-IAP): Independent variables: age, sex, IAP, $A R P I$, type of surgery and duration of surgery

Odds ratios (OR) and $95 \% \mathrm{Cls}$ were calculated to evaluate the strength of any association that emerged. The receiver operating characteristic (ROC) curve was used to evaluate the discriminative ability of each model for patients with and without re-operation, based on the sensitivity and specificity values for each point of the curve. The discriminative power of the model was considered excellent if the area under 


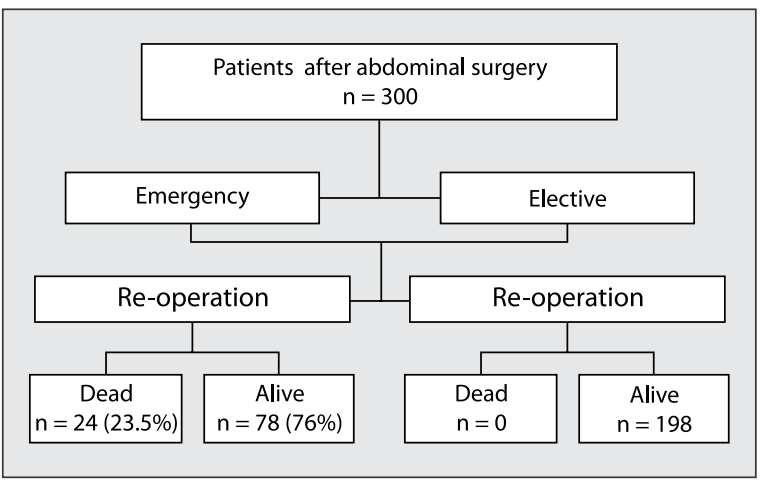

Figure 3. Main characteristics of the study population

the curve (AUC) was $>0.80$, very good if $>0.75$, and good if $>0.70$ [10]. The calibration of each model was assessed by the Hosmer-Lemeshow goodness-of-fit statistical test. For the Hosmer-Lemeshow statistical test, $P>0.05$ was considered to indicate acceptable calibration of the model.

\section{ETHICAL CONSIDERATIONS}

The protocol was approved by the hospital's ethics committee (ref: 123/2007), and informed consent was provided by patients, or next of kin, before study inclusion. IAP measurements did not interfere with other diagnostic or therapeutic procedures, according to the Helsinki Declaration [11].

\section{RESULTS}

Three hundred post-abdominal surgery patients were included in this study. Emergency surgery was performed in 265 (88\%) while the remainder comprised elective patients (Fig. 3). One hundred and two (34\%) patients were re-operated on while $24(23.52 \%)$ patients died. There was zero mortality in the 198 (66\%) patients that did not undergo repeat surgery.

Although the EG and VG were similar in terms of gender, comorbidity, re-operation, malignancy, IAP values, APACHE II and mortality, the VG had a higher mean age (Table 1).

The most common findings at the primary operation were acute appendicitis, followed by intestinal obstruction and acute cholecystitis (Table 2).

At re-operation the most frequent findings were intraabdominal abscesses and suture leakage with peritonitis (23.5\%) (Table 3). Twelve patients did not have any pathological findings on re-operation.

In model I (ARPI) the ARPI, gender and duration of surgery had coefficients significantly different from zero $(P<$ 0.05). The odds ratio for ARPI was 1.355 (95\% Cl: 1.245-1.475) $P<0.001$. ARPI had the greatest influence (standard coefficient 2.656) on the probability of being re-operated on. This model has an excellent discrimination, with AUC $>0.92$ in the two groups (Fig. 4).
Table 2. Findings at primary operation

\begin{tabular}{lcc}
\hline Diagnosis at operation & $\mathbf{n}$ & $\%$ \\
\hline Colonic neoplasm & 10 & 3.3 \\
Perforated colonic diverticulitis & 18 & 6 \\
Intestinal obstruction & 43 & 14.3 \\
Acute appendicitis & 111 & 37 \\
Perforated peptic ulcer & 23 & 7.7 \\
Gastric cancer & 6 & 2 \\
Acute cholecystitis & 37 & 12.3 \\
Acute pancreatitis & 3 & 1 \\
Gynaecological peritonitis & 9 & 3 \\
Others & 40 & 13.3 \\
Total & 300 & 100 \\
\hline
\end{tabular}

Table 3. Findings at re-operation

\begin{tabular}{lc}
\hline Findings & $\mathbf{n}(\%)$ \\
\hline Intra-abdominal abscesses & $24(23.5)$ \\
Generalized peritonitis & $12(11.8)$ \\
Localized peritonitis & $12(11.8)$ \\
Suture leakage with peritonitis & $24(23.5)$ \\
Intestinal necrosis & $3(3.0)$ \\
Abdominal wall necrosis with localized peritonitis & $9(8.8)$ \\
Choleperitoneum & $6(5.9)$ \\
No pathological findings & $12(11.8)$ \\
Total & $102(100)$ \\
\hline
\end{tabular}

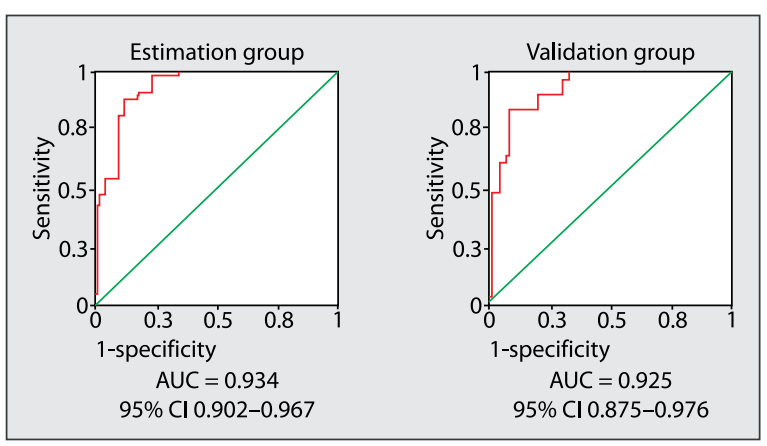

Figure 4. Model I (ARPI). Receiver operating characteristic curve $(\mathrm{ROC})$ in the estimation and validation groups

In model II (IAP), only IAP had coefficients significantly different from zero $(P<0.05)$. The odds ratio was $2.61(95 \% \mathrm{Cl}$ : 1.86-3.65) and was significant $(P=0.00)$. In this cohort, IAP had the greatest influence on the probability of re-operation. This model also had an excellent performance with AUC > 0.95 in the two groups (Fig. 5). 


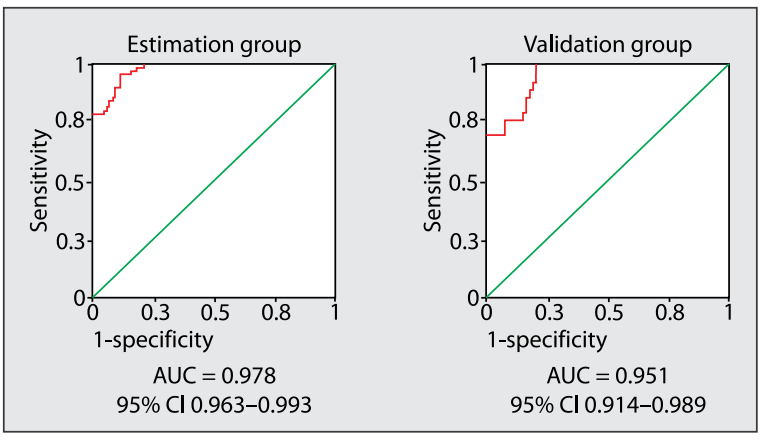

Figure 5. Model II (IAP). Receiver operating characteristic curve (ROC) in the estimation and validation groups

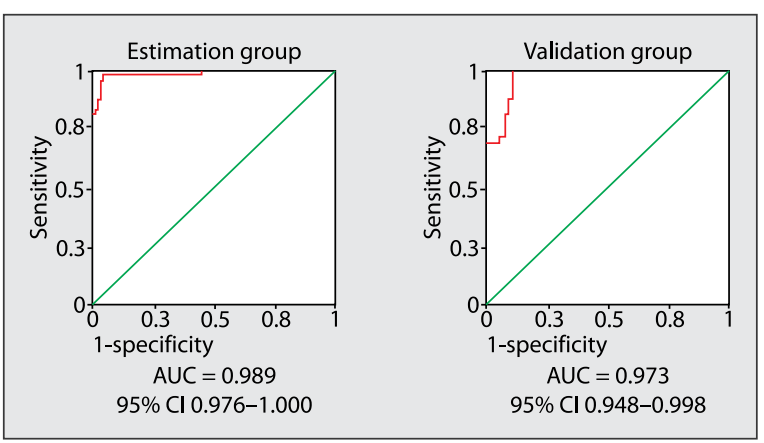

Figure 6. Model III (ARPI-IAP). Receiver operating characteristic curve $(\mathrm{ROC})$ in the estimation and validation groups

Table 4. Statistical models developed

\begin{tabular}{ll}
\hline Model & Equation \\
\hline I: ARPI & $\mathrm{P}(\mathrm{y}=1)=1 /\left(1+\mathrm{EXP}\left[3.557+0.001^{*}\right.\right.$ age $+0.914^{*}$ gender \\
& $+0.017^{*}$ duration of surgery- $0.304^{*} \mathrm{ARPI}-$ \\
& $1.356^{*}$ type of surgery $\left.)\right]$ \\
II: IAP & $\mathrm{P}(\mathrm{y}=1)=1 /\left(1+\mathrm{EXP}\left[14.448-0.031^{*}\right.\right.$ age- $0.111^{*}$ gender \\
& $+0.007^{*}$ duration of surgery- $0.222^{*}$ type of \\
& surgery- $0.958^{*}$ IAP $\left.)\right]$ \\
III: ARPI-IAP & $\mathrm{P}(\mathrm{y}=1)=1 /\left(1+\mathrm{EXP}\left[15.835-0.041^{*}\right.\right.$ age- $0.263^{*}$ gender- \\
& $0.895^{*} \mathrm{IAP}+0.029^{*}$ duration of surgery- $0.311^{*} \mathrm{ARPI}$ \\
& $-0.042^{*}$ type of surgery $\left.)\right]$
\end{tabular}

In model III (ARPI-IAP), the IAP, ARPI and duration of surgery had coefficients different from zero. The odds ratio related to ARPI, IAP and duration of surgery were 1.365, 2.448 and 0.971 respectively. The most influential variable on the probability for re-operation was IAP, followed by ARPI. This model had the best discrimination, with AUC $>0.97$ in the two groups (Fig. 6).

The Hosmer-Lemeshow test $(P>0.05)$ demonstrated good adjustment and excellent calibration in the EG (internal validation) group. In the external validation group, the three models did not show significant probability associated to the Hosmer-Lemeshow test $(P>0.05)$, thus revealing excellent calibration (Table 5). Discrimination was also excellent. Figure 7 compares the ROC curves of the three models.

\section{DISCUSSION}

The index scores related to the need for re-operation were selected to create the mathematical models, based on previous studies [2, 12-23]. In our cohort of patients, age was not recognized as an independent risk factor, although Pusajó et al. [1] found it to be associated with re-operation. Male gender was only included as a risk factor in model III (ARPI-IAP). In general, gender was not a significant risk factor

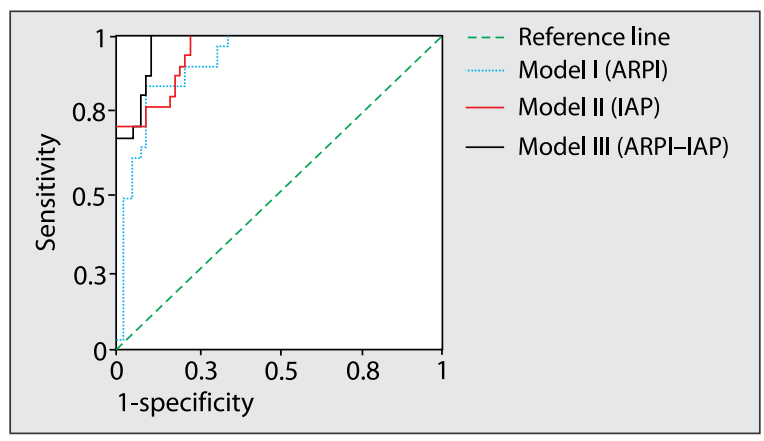

Figure 7. Receiver operating characteristic curve (ROC) comparison between the three models, $P=0.001$

Table 5. Calibration and discrimination of the three models for re-operation based on prognostic indexes in patients' post-abdominal surgery

\begin{tabular}{|c|c|c|c|c|c|c|c|c|}
\hline \multirow[t]{3}{*}{ Model } & \multicolumn{4}{|c|}{$\begin{array}{l}\text { Internal validation } \\
\text { (estimation group) }\end{array}$} & \multicolumn{4}{|c|}{$\begin{array}{l}\text { External validation } \\
\text { (validation group) }\end{array}$} \\
\hline & \multicolumn{2}{|c|}{ Hosmer-Lemeshow } & \multicolumn{2}{|c|}{ ROC } & \multicolumn{2}{|c|}{ Hosmer-Lemeshow } & \multicolumn{2}{|c|}{ ROC } \\
\hline & $C$ & $p$ & AUC & $95 \% \mathrm{Cl}$ & $C$ & $p$ & AUC & $95 \% \mathrm{Cl}$ \\
\hline ARPI & 8.17 & 0.42 & 0.94 & $0.90-0.97$ & 1.44 & 0.23 & 0.93 & $0.88-0.98$ \\
\hline IAP & 4.02 & 0.86 & 0.98 & $0.96-0.99$ & 0.04 & 0.84 & 0.95 & $0.91-0,99$ \\
\hline ARPI-IAP & 9.98 & 0.27 & 0.99 & $0.86-1.00$ & 0.58 & 0.45 & 0.97 & $0.58-0.99$ \\
\hline
\end{tabular}

ARPI — acute re-operation prognostic index; IAP — intra-abdominal pressure; ROC — receiver operating characteristic curve; AUC - area under the curve; C - Hosmer-Lemeshow statistical test: $\mathrm{Cl}$ - confidence interval 
for re-operation. Previous study findings are controversial and gender is not clearly associated with re-operation [24-28].

Although comorbidities in our cohort were frequent, they were not included as independent predictors for re-operation as the association was not significant. Comorbidities were present in almost all the patients, those re-operated on or not.

Malignancy has been reported as an adverse condition for surgical outcome [29]. Suture leakage with peritonitis, progression to bacterial peritonitis (sometimes associated to pre-surgical radiotherapy), and the occurrence of adverse events during the perioperative period are more frequent [29]. However, malignancy was not recognized as a risk factor for re-operation in this study. This may be explained by the low prevalence of this pathology in the study population.

The type of surgery was also found to be an insignificant factor in determining the probability of re-operation, despite this usually being associated with morbidity and mortality. Emergency surgery is associated with higher morbidity and mortality [30] as a consequence of complications from organ failure. However, Van Ruler et al. [31] confirmed that the main reason for this was not the type of surgery, but rather the magnitude of the pathological insult and surgery [31].

Mathematically derived models can help reveal relationships that are otherwise not easily identified [32]. In this study, the duration of surgery had a protective effect in relation to the intervention $(\mathrm{OR}=0.971,95 \% \mathrm{Cl}: 0.971-0.996$, $P=0.025)$ with negative adjusted and standardized coefficients (Coef $(b)=-0.029$ Coef $(b) E a=-1.296)$. This was an unexpected and paradoxical result in our patient population where more than $80 \%$ of the surgery was emergent (265 patients). Patients who already had a planned re-operation scheduled were also excluded, independent of the characteristics of the first intervention or their APACHE II score. These results may be explained in part by the duration of surgery being influenced by a combination of objective and subjective factors, related to process and structure indicators (for example, the operating theatre, efficiency, efficacy of management) [33] and including the learning curve for the junior surgeons [34, 35].

This subject remains controversial. For example, minimal access surgery (MAS) requires a longer operating time to ensure its quality. Several authors report longer operating times for MAS compared with the same procedure performed during open surgery [35-37]. However, as the operating time increases, so does the risk of infection, the possibilities of fluid, electrolyte and immunologic disturbances (release of cytokines and other inflammatory mediators) $[38,39]$. In support of longer operating times is the ability for the surgeon to potentially pay more attention to detail and precision. These factors are well established, especially in oncologic surgery [17]. In recent years, authors have de- scribed the association between anastomotic leakage, peritoneal infection and recurrence in oncologic surgery, thus supporting meticulous and precise attention to detail and surgical technique [17]. Gil-Bona et al. [40], however, found that duration of surgery was not a contributing factor to surgical mortality, but rather to intra-operative complications.

There are significant statistical differences between the three models. Though all of them provide excellent discrimination and are well calibrated, it is possible to establish a hierarchy. Model III offers the best ROC, with the best AUC (0.973; 95\% Cl: 0.948-0.998). Although three models had excellent performance concerning calibration and discrimination, while the difference between the three AUCs was significant (chi-squared test 10.172, $P=0.001$ ). Model III (ARPI and IAP) had the best AUC and is the most useful for predicting the probability of re-operation (Fig. 7). The best discrimination is provided by model III (ARPI-IAP), followed by model II (IAP). This model identified those patients with a real probability of developing intra-abdominal sepsis. This is a very important clinical finding. The association of both systems includes the logical principle introduced by the Boolean "AND" operator (the "AND rule") [41]. This improves diagnostic sensitivity and specificity and helps surgeons' and intensivists' decision-making when facing a patient with suspected intra-abdominal sepsis. This proposed model would support clinical findings and help predict which critically ill patients require re-operation following abdominal surgery.

Pusajó et al. [1] proposed the ARPI, while Basu et al. [42] used the increased IAP $(P=0.055)$ as re-operation criteria in patients with secondary bacterial peritonitis. To our knowledge, this is the first study that has combined these variables in statistical models.

This study had several limitations, including a higher (than previously reported) mortality rate in those patients who were re-operated on. This could affect the external validation, although the patients included were severely ill, with APACHE II scores above thirteen. The mortality rate was in correspondence with the severity of the peritonitis the patients initially presented with. Clinical assessment always guided the decision-making process and was thus taken into account when developing the models. There was, however, no comparison with radiological imaging data available, hence the peri-operative findings were deemed the gold standard.

\section{CONCLUSIONS}

An accurate mathematical model, able to predict the need for abdominal surgery, was developed by combining prognostic factors related to abdominal re-operation in critically ill surgical patients. The ARPI-IAP model was the most accurate, followed by the IAP model. This was more ac- 
curate than using either ARPI or IAP on their own. Although this ARPI-IAP model is a potentially useful clinical tool in all settings, its may be especially helpful in medical centres with limited radiological resources, including disaster and war zones.

\section{ACKNOWLEDGEMENTS}

Manu L.N.G. Malbrain is member of the medical advisory board of Pulsion Medical Systems (Maquet Getinge) and Holtech Medical and consults for Kinetic Concepts International and ConvaTec. The other authors have no possible conflicts of interest with regard to the contents of this paper. Parts of this paper have been published previously in Spanish and were published as Open Access under the Attribution-NonCommercial 4.0 International (CC BY-NC 4.0) Licence. The English translation was performed after written permission from all co-authors and the publisher. (http:// www.arsmedica.cl/index.php/MED/article/view/56/325).

\section{References:}

1. Pusajó J. Postoperative Intra-abdominal Sepsis Requiring Reoperation. Archives of Surgery. 1993; 128(2): 218, doi: 10.1001/archsurg.1993.01420140095015.

2. Lombardo Vaillant T A, Soler Morejón C, Lombardo Vaillant J, Casamayor Laime Z. Aplicación del índice predictivo de reintervención abdominal en el diagnóstico de complicaciones infecciosas intraabdominales. Rev Cub Med Mil. http://scielo.sld.cu/scielo.php?script=sci_arttext\&pi$\mathrm{d}=$ S0138-65572009000100002\&lng=es\&nrm=iso (1.01.2010).

3. Sartelli M, Catena F, Abu-Zidan FM, et al. Management of intra-abdominal infections: recommendations by the WSES 2016 consensus conference. World J Emerg Surg. 2017; 12: 22, doi: 10.1186/s13017017-0132-7, indexed in Pubmed: 28484510.

4. van Ruler O, Kiewiet JJS, Boer KR, Lamme B, Gouma DJ, Boermeester MA et al. Failure of available scoring systems to predict ongoing infection in patients with abdominal sepsis after their initial emergency laparotomy. BMC Surgery. http://www.biomedcentral.com/1471-2482/11/38 (19.01.207).

5. Cook NR. Statistical evaluation of prognostic versus diagnostic models: beyond the ROC curve. Clin Chem. 2008; 54(1): 17-23, doi: 10.1373/ clinchem.2007.096529, indexed in Pubmed: 18024533.

6. Khan S, Verma AK, Ahmad SM, et al. Analyzing intra-abdominal pressures and outcomes in patients undergoing emergency laparotomy. J Emerg Trauma Shock. 2010; 3(4): 318-325, doi: 10.4103/09742700.70747, indexed in Pubmed: 21063552.

7. Cheatham M, Safcsak K. Intra-abdominal pressure: A revised method for measurement. J Am Coll Surg. 1998; 186(5): 594-595.

8. Kirkpatrick AW, Roberts DJ, De Waele J, et al. Pediatric Guidelines Sub-Committee for the World Society of the Abdominal Compartment Syndrome. Intra-abdominal hypertension and the abdominal compartment syndrome: updated consensus definitions and clinical practice guidelines from the World Society of the Abdominal Compartment Syndrome. Intensive Care Med. 2013; 39(7): 1190-1206, doi: 10.1007/ s00134-013-2906-Z, indexed in Pubmed: 23673399.

9. Knaus WA, Zimmerman JE, Wagner DP, et al. APACHE-acute physiology and chronic health evaluation: a physiologically based classification system. Crit Care Med. 1981; 9(8): 591-597, indexed in Pubmed: 7261642.

10. Swets JA. Measuring the accuracy of diagnostic systems. Science. 1988; 240(4857): 1285-1293, indexed in Pubmed: 3287615.

11. World Medical Association Declaration of Helsinki. Ethical Principles for Medical Research Involving Human Subject. 59th WMA General Assembly, Seoul, October 2008.

12. Shinkawa $H$, Yasuhara $H$, Naka $S$, et al. Factors affecting the early mortality of patients with nontraumatic colorectal perforation. Surg Today. 2003; 33(1): 13-17, doi: 10.1007/s005950300002, indexed in Pubmed: 12560901.
13. Pisanu A, Cois A, Uccheddu A. Surgical treatment of perforated diverticular disease: evaluation of factors predicting prognosis in the elderly. Int Surg. 2004; 89(1): 35-38, indexed in Pubmed: 15085996.

14. Mäkelä JT, Kiviniemi H, Laitinen S. Prognostic factors of perforated sigmoid diverticulitis in the elderly. Dig Surg. 2005; 22(1-2): 100-106, doi: 10.1159/000085472, indexed in Pubmed: 15849471.

15. Komatsu S, Shimomatsuya T, Nakajima M, et al. Prognostic factors and scoring system for survival in colonic perforation. Hepatogastroenterology. 2005; 52(63): 761-764, indexed in Pubmed: 15966200.

16. Yeh $C Y$, Changchien $C R$, Wang JY, et al. Pelvic drainage and other risk factors for leakage after elective anterior resection in rectal cancer patients: a prospective study of 978 patients. Ann Surg. 2005; 241(1): 9-13, indexed in Pubmed: 15621985.

17. Rakić M, Popović D, Rakić M, et al. Comparison of on-demand vs planned relaparotomy for treatment of severe intra-abdominal infections. Croat Med J. 2005; 46(6): 957-963, indexed in Pubmed: 16342350.

18. Filgueiras Ramos B, Bembibre Taboada R, Corona Martínez LA, Soler Morejón C. Monitoreo de la presión intraabdominal (PIA) en el paciente quirúrgico grave. Rev Cubana Cir [revista en la Internet]. 2001 Mar [citado 2011 Mar 08] 40(1): 18-23. . http://scielo.sld.cu/scielo. php?script=sci_arttext\&pid=S003474932001000100003\&lng=es.

19. Panhofer $\mathrm{P}$, Izay B, Riedl M, et al. Age, microbiology and prognostic scores help to differentiate between secondary and tertiary peritonitis. Langenbecks Arch Surg. 2009; 394(2): 265-271, doi: 10.1007/ s00423-008-0301-y, indexed in Pubmed: 18343942.

20. Reyes de la Paz A, Lombardo Vaillant TA, Rubio Olivares DY. Valor predictivo de la presión intra-abdominal en el diagnóstico de complicaciones posoperatorias abdominales. Rev Cubana Med Mil 2007; 36(4). http://scielo.sld.cu/scielo.php?script=sci_artte$x t \& p i d=S 013865572007000400003 \& \operatorname{lng}=e s \& n r m=i s o(20.04 .2017)$.

21. Koperna T, Schulz F. Relaparotomy in peritonitis: prognosis and treatment of patients with persisting intraabdominal infection. World J Surg. 2000; 24(1): 32-37, indexed in Pubmed: 10594200.

22. Pera $M$, Pascual M. Estándares de calidad de la cirugía del cáncer de recto. Gastroenterología y Hepatología. 2005; 28(7): 417-425, doi: $10.1157 / 13077763$.

23. Pera M. Dehiscencia de anastomosis y recurrencia del cáncer colorrectal: una asociación que refuerza el valor pronóstico del cirujano en el resultado oncológico. Cirugía Española. 2011; 89(2): 69-71, doi: 10.1016/j.ciresp.2010.09.010.

24. Wacha H, Linder MM, Feldman U. Mannheim Peritonitis Index: Prediction of risk of death from peritonitis. Construction of a statistical and validation of an empirically based index. Theoret Surg. 1987; 1: 169-177.

25. Biondo S, Ramos E, Fraccalvieri D, et al. Comparative study of left colonic Peritonitis Severity Score and Mannheim Peritonitis Index. Br J Surg. 2006; 93(5): 616-622, doi: 10.1002/bjs.5326, indexed in Pubmed: 16607684.

26. Aydin C, Altaca G, Berber I, et al. Prognostic parameters for the prediction of acute gangrenous cholecystitis. J Hepatobiliary Pancreat Surg. 2006; 13(2): 155-159, doi: 10.1007/s00534-005-1042-8, indexed in Pubmed: 16547678.

27. Asai K, Hiki N, Mimura Y, et al. Gender differences in cytokine secretion by human peripheral blood mononuclear cells: role of estrogen in modulating LPS-induced cytokine secretion in an ex vivo septic model. Shock. 2001; 16(5): 340-343, indexed in Pubmed: 11699070.

28. Schröder J, Kahlke V, Staubach $\mathrm{KH}$, et al. Gender differences in human sepsis. Arch Surg. 1998; 133(11): 1200-1205, indexed in Pubmed: 9820351.

29. Lee WS, Yun SH, Roh YN, et al. Risk factors and clinical outcome for anastomotic leakage after total mesorectal excision for rectal cancer. World J Surg. 2008; 32(6): 1124-1129, doi: 10.1007/s00268007-9451-2, indexed in Pubmed: 18259805.

30. Okubo R, Yajima K, Sakai Y, et al. Short-and long-term outcomes of surgery for diffuse peritonitis in patients 80 years of age and older. Surg Today. 2008; 38(5): 413-419, doi: 10.1007/s00595-007-3658-6, indexed in Pubmed: 18560963.

31. van Ruler O, Mahler CW, Boer KR, et al. Dutch Peritonitis Study Group. Comparison of on-demand vs planned relaparotomy strategy in patients with severe peritonitis: a randomized trial. JAMA. 2007; 298(8): 865-872, doi: 10.1001/jama.298.8.865, indexed in Pubmed: 17712070. 
32. Montesinos-López O, Hernández-Suárez C. Modelos matemáticos para enfermedades infecciosas. Salud Pública de México. 2007; 49(3): 218-226, doi: 10.1590/s0036-36342007000300007.

33. Donabedian A, Donabedian A. Evaluating the quality of medical care. The Milbank Quarterly. 2005; 83(4): 691-729.

34. Kim SYi, Hong SG, Roh HR, et al. Learning curve for a laparoscopic appendectomy by a surgical trainee. J Korean Soc Coloproctol. 2010; 26(5): 324-328, doi: 10.3393/jksc.2010.26.5.324, indexed in Pubmed: 21152134.

35. Haji A, Khan A, Haq A, et al. Elective laparoscopic cholecystectomy for surgical trainees: predictive factors of operative time. Surgeon. 2009; 7(4): 207-210, indexed in Pubmed: 19736886.

36. Khalil J, Muqim R, Rafique $M$, et al. Laparoscopic versus open appendectomy: a comparison of primary outcome measures. Saudi J Gastroenterol. 2011; 17(4): 236-240, doi: 10.4103/1319-3767.82574, indexed in Pubmed: 21727728.

37. Khan MN, Fayyad T, Cecil TD, et al. Laparoscopic versus open appendectomy: the risk of postoperative infectious complications. JSLS. 2007; 11(3): 363-367, indexed in Pubmed: 17931520.

38. Desborough JP. The stress response to trauma and surgery. Br J Anaesth. 2000; 85(1): 109-117, indexed in Pubmed: 10927999.

39. Hotchkiss RS, Darl IE. The pathophysiology and treatment of sepsis. N Engl Med. 2003; 348: 138-150.
40. Gil-Bona J, Sabaté A, Bovadilla JM, et al. Valor de los índices de Charlson y la escala de riesgo quirúrgico en el análisis de la mortalidad operatoria. Cirugía Española. 2010; 88(3): 174-179, doi: 10.1016/j.ciresp.2010.05.012.

41. Weinstein S, Obuchowski NA, Lieber ML. Clinical evaluation of diagnostic tests. AJR Am J Roentgenol. 2005; 184(1): 14-19, doi: 10.2214/ ajr.184.1.01840014, indexed in Pubmed: 15615943.

42. Basu A, Pai DR. Early elevation of intra-abdominal pressure after laparotomy for secondary peritonitis: a predictor of relaparotomy? World J Surg. 2008; 32(8): 1851-1856, doi: 10.1007/s00268-008-9605-x, indexed in Pubmed: 18488267.

\section{Corresponding author:}

Caridad de Dios Soler-Morejón

San Lázaro \#751 entre Belascoaín

y Marqués González, Centro Habana, CP 10300

e-mail:csoler@infomed.sld.cu

Received: 13.09.2017

Accepted: 11.11.2017 